\title{
ESTUDO DA ADIÇÃO DE LODO GERADO PELA INDÚSTRIA METAL MECÂNICA NA FABRICAÇÃO DE TIJOLOS DE CERÂMICA VERMELHA
}

Geovane Vieira $^{1}$

Douglas Fernando da Silva²

\begin{abstract}
RESUMO
Este trabalho teve como objetivo avaliar a incorporação do lodo gerado na Estação de tratamento de efluentes-ETE de uma indústria de produção de refrigeradores, na matéria prima de fabricação de tijolos furados e maciços de cerâmica vermelha. $O$ lodo foi caracterizado através da análise de fluorescência de raios- $X$, difratometria de raios- $X$, e seu comportamento térmico analisado por termogravimetria e calorimetria exploratória diferencial. As composições foram preparadas nas proporções de 10, 15 e 20 \% de lodo em massa de cerâmica vermelha. Foram produzidos corpos de prova sinterizados na temperatura de $800,900,950$ e $1050{ }^{\circ} \mathrm{C}$. Para cada mistura, foram medidas as propriedades de perda ao fogo, retração térmica linear de queima, retração térmica devido a secagem, absorção de água, cor de queima, massa específica aparente, porosidade, granulometria, resistência a compressão, umidade e a plasticidade. As composições de 10 e 15 \% apresentaram resultados muito promissores em relação aos requisitos recomendados
\end{abstract}

Palavras chaves: lodo. Cerâmica vermelha. Tijolos. Propriedades mecânicas

${ }^{1}$ Mestre; e-mail:geovane.vieira@sc.senai.br / gvieira@mexichem.com.br

2Mestre; e-mail:douglafs@whirlpool.com / douglafs@gmail.com 


\section{INTRODUÇÃO}

Com o crescimento econômico as indústrias passam a produzir em escalas cada vez maiores, com isso a maior parte das indústrias com processos pouco desenhados para minimização de impactos ambientais, geram resíduos cada vez mais difíceis de serem degradados pela natureza, e em quantidades cada vez maiores.

Jianlong e Jiazhuo (2007) menciona que a produção de lodo de efluente tem atingido uma dimensão alarmante como crescimento da população urbana, com a melhoria da qualidade de vida e o desenvolvimento da indústria e agricultura. É estimado que aproximadamente $26 \mathrm{Kg}$ de lodo sejam gerados por pessoa por ano, numa base de massa seca. Aproximadamente 4000 toneladas de lodo de efluente são produzidas cada dia na Coréia. Nos Estados Unidos da América, mais de 2 bilhões de dólares são gastos anualmente no tratamento e aproximadamente de 5 a 7 milhões de toneladas secas de biosólidos são processadas por mais de 13000 empresas que trabalham com o tratamento. Na China, estima-se que o lodo de efluente produzido em 2005 pode ter alcançado 3.5 milhões de toneladas. (JIANLONG; JING, 2007).

Geralmente, as peças que terão superfícies tratadas ou pintadas já apresentam como produtos quase prontos, ou seja, trefilados, fundidos, forjados e estampados. As superfícies das peças nestas condições não podem ser tratadas imediatamente porque, normalmente apresentam resíduos de óleo, trincas, restos de graxas e abrasivos de polimentos. Neste caso, é necessário um pré-tratamento das superfícies, de modo que elas fiquem bastante limpas antes do tratamento propriamente dito (FIESP, 1996 apud AGUIAR, 2007, p. 54).

A nanotecnologia é um conceito em se aplicar ou incorporar às superfícies metálicas (metais ferrosos ou não ferrosos) partículas nano-estruturadas que, após sua deposição e secagem, assumem uma característica nanocerâmica em virtude de a camada ser constituída de óxidos. Esta característica faz com que a camada aplicada seja mínima e uniforme, o que confere as mesmas propriedades especiais no recebimento da camada de tinta, tais como: aderência flexibilidade, ausência de efeito revelador de fundo e aumento da resistência à corrosão se comparando com o fosfato de ferro e de zinco convencional (BOSSARDI, 2007).

Apesar da tecnologia com processos nanocerâmicos estar sendo considerada como processos ecologicamente corretos (BOSSARDI, 2007), pela isenção de metais pesados, a geração de lodo ainda permanece na ETE. E, da mesma forma com o tratamento com fosfato, o resíduo sólido continua a ocupar espaço físico e a carregar consigo, resíduos provenientes da limpeza das superfícies.

Desta forma, o objetivo geral deste projeto é realizar a incorporação do lodo gerado na Estação de Tratamento de Efluentes (ETE) de uma indústria de produção de refrigeradores, na matéria prima de fabricação de tijolos furados e maciços de cerâmica vermelha. Com a incorporação deste resíduo na matéria prima de fabricação de tijolos pretende-se diminuir a quantidade de lodo encaminhada ao aterro industrial. 
Para alcançar o objetivo macro deste projeto será realizada a caracterização do lodo gerado na ETE da indústria mecânica; realizar a classificação deste lodo gerado e incorporá-lo na matéria prima de tijolos furados e maciços de cerâmica vermelha. O outro objetivo é realizar os diversos ensaios físicos mecânicos da mistura para avaliar tecnicamente a possibilidade de incorporação do lodo gerado na ETE da indústria mecânica, na matéria prima de fabricação de tijolos furados e maciços de cerâmica vermelha.

\section{RESÍDUOS SÓLIDOS}

O lodo gerado durante os vários processos industriais pode conter níveis altos de metais tóxicos, e estes níveis excessivos de metais pesados, quando introduzidos ao solo através do lodo podem ser absorvidos e causar danos à saúde das plantas e do homem (NAIR; JUWARKAR; DEVOTTA, 2007, p. 1).

De acordo com a Associação Brasileira de Normas Técnicas (2004), a classificação para o gerenciamento dos resíduos sólidos é estabelecida por dois grupos: os da Classe I Perigosos: são resíduos que, em função de suas características de inflamabilidade, corrosividade, reatividade, toxicidade e patogenicidade, podem apresentar risco à saúde pública. E os da Classe II Não perigosos, sendo que esses últimos estão subdivididos em Classe II A Não inertes e Classe II B Inertes. O resíduo classe II B Não inertes podem ter propriedades de combustibilidade, biodegradabilidade ou solubilidade em água. Já os da Classe II B Inertes são resíduos que não possuem em nenhum de seus constituintes solubilizados, concentrações superiores aos padrões definidos na Listagem $\mathrm{G}$ da mesma norma.

\section{RECICLAGEM DE RESÍDUOS NA INDÚSTRIA CERÂMICA}

Os métodos de deposição em aterro, aplicação na terra e incineração são os modos atuais dominantes de dar destino aos lodos das plantas de tratamento de águas residuárias (SVANSTRÖM et al., 2004 apud STARK, 2005, p. 2).

Uma alternativa ecologicamente correta para a destinação final do lodo, proveniente da indústria metal mecânica, seria a possibilidade do seu aproveitamento como matéria prima na indústria cerâmica. Visto que a matéria prima empregada possui certas características semelhantes ao do lodo, tais como plasticidade quando molhado e dureza quando seco.

Vários estudos já foram realizados visando à utilização de resíduos industriais oriundos de diversos processos de fabricação em massas cerâmicas, entre eles podem-se citar: 
Amorim (2007) estudou o uso de dregs em argila para produção de materiais de cerâmica vermelha. Avaliou várias formulações, temperatura e ciclos de queima e concluiu que é uma alternativa viável para utilização.

Lopes (2005) avaliou a viabilidade de adição de resíduo de pó de fumo na massa cerâmica para fabricação de tijolos maciços, blocos e telhas. Os ensaios de lixiviação realizados com um copo de prova contendo $15 \%$ de adição de resíduo e outro contendo $10 \%$ indicam valores dentro das faixas de aceitação indicadas pela NBR 10004/04

Ribeiro (2008) em sua pesquisa provou que alguns tipos de resíduos industriais (resíduos siderúrgicos - pós de exaustão e areias de fundição) além de outros tipos de resíduos como vidro residual e sais de inertização com argila natural podem ser usados para a fabricação de cerâmica vermelha (tijolos, telhas, pisos, azulejos, etc.) de construção civil.

Paranhos (2010) utilizou cinza do bagaço da cana de açúcar na massa cerâmica para obtenção de um grés porcelanato. Ficou comprovada, após resultado dos ensaios realizados, que é possível a utilização do resíduo com adição de até $10 \%$ em peso na massa cerâmica.

Tartari (2008) incorporou lodo gerado na estação de tratamento de água Tamanduá em Foz do Iguaçú - PR como aditivo em massas para cerâmica vermelha. Os resultados mostraram que os ensaios físicos mecânicos ficaram dentro das normas para produção de tijolo com $6 \%$ de lodo adicionado à massa.

\section{MATERIAIS E MÉTODOS}

Para realização da caracterização, foi coletado lodo proveniente da Estação de Tratamento de Efluentes (ETE) da empresa Whirlpool Unidade de Eletrodomésticos em Joinville localizada na estrada Dona Francisca - Distrito Industrial da cidade de Joinville. Sua classificação foi realizada pela Orgânica Laboratório de Análises Químicas LTDA situada em Jaraguá do Sul, SC. A análise de FRX do resíduo foi realizada no Laboratório de Materiais Cerâmicos da Universidade Estadual de Ponta Grossa (UEPG), em Ponta Grossa, PR. As análises térmicas e DRX foram realizadas no Laboratório de Caracterização de materiais da Universidade Estadual de Santa Catarina (UDESC), em Joinville, SC.

Para realização dos ensaios físicos mecânicos foram utilizados além do lodo comentado acima, massa argilosa para fabricação de cerâmica vermelha do município Joinville. Os ensaios foram realizados no Laboratório de Desenvolvimento e Caracterização de Materiais (LDCM) do SENAI Criciúma, SC. 


\subsection{Classificação do lodo}

Uma primeira análise foi realizada com o resíduo a fim de obter sua classificação conforme a norma ABNT NBR10004/04.

Para todos os elementos estudados, foram realizadas preparação e abertura da amostra separadamente, como é descrito no Standard Methods for Examination of Water and Wastewater 20th Edition.

\subsection{Caracterização do lodo}

A massa padrão foi caracterizada quanto à sua composição química por fluorescência de raios-x (FRX) com o equipamento Shimadzu modelo EDX-700. Para identificação da estrutura cristalina do resíduo, foi utilizado o difratômetro Shimadzu (XDR 6000) com tubo de raios $X$ de cobre, voltagem $40 \mathrm{kV}$ e corrente $30 \mathrm{~mA}$. A leitura foi realizada no eixo de direção $2 \theta$, entre $5 \circ$ e 80 o com velocidade de $2 \% / \mathrm{min}$. A análise térmica foi realizada em um analisador térmico da marca Netzsch, modelo STA 449C Júpiter com uma faixa de aquecimento de $30^{\circ} \mathrm{C}$ a $1200{ }^{\circ} \mathrm{C}$ por 2 horas. A massa da amostra de lodo utilizada para análise térmica foi de $28.55 \mathrm{~g}$. O cadinho em alumina com massa da amostra $154 \mathrm{~g}$ foi utilizado para realizar a análise térmica. $O$ gás de aquecimento utilizado foi o argônio a uma taxa de $30 \mathrm{ml} / \mathrm{min}$ além do uso do gás protetivo nitrogênio a uma taxa de $15 \mathrm{ml} /$ $\min$. E a taxa de aquecimento utilizada foi de $10^{\circ} \mathrm{C} / \mathrm{min}$.

\subsection{Ensaios físicos mecânicos}

Para realização destes ensaios foram usadas as composições de 10,15 e $20 \%$ lodo na massa de argila.

Os corpos de prova, nas dimensões de $23 \times 93 \times 7 \mathrm{~mm}$, e compactados a uma pressão de $19 \mathrm{MPa}$., foram queimados nas temperaturas de $800^{\circ} \mathrm{C}, 900^{\circ} \mathrm{C}, 950^{\circ} \mathrm{C}$ e $1050^{\circ} \mathrm{C}$ durante $180 \mathrm{~min}$, a uma taxa de aquecimento de $5^{\circ} \mathrm{C} / \mathrm{min}$.

Após obtenção dos corpos de prova, foram realizados os ensaios para obtenção de Umidade de Extrusão, Plasticidade - NBR 7180/84 (ASSOCIAÇÃO BRASILEIRA DE NORMAS TÉCNICAS, 1984b) e NBR 6459/84 (ASSOCIAÇÃO BRASILEIRA DE NORMAS TÉCNICAS, 1984a), Granulometria, Retração Linear de Secagem, Resistência a Compressão - NBR 15270-3/05, Absorção de água - NBR 15270-3/05, (ASSOCIAÇÃO BRASILEIRA DE NORMAS TÉCNICAS, 2005b) Retração Linear de Queima, Massa Específica Aparente, Porosidade NBR 6220/89, (ASSOCIAÇÃO BRASILEIRA DE NORMAS TÉCNICAS, 1989) Perda ao Fogo e Cor de Queima. 


\section{RESULTADOS E DISCUSSÕES}

\subsection{Classificação do resíduo}

Os resultados da classificação do lodo são apresentados na Tabela 1 e Tabela 2. Conforme os resultados das análises o material atendeu a todos os parâmetros, com exceção da concentração de Alumínio que ficou acima do limite estabelecido para material solubilizado, conforme anexo G da norma ABNT NBR 10004/04 (ASSOCIAÇÃO BRASILEIRA DE NORMAS TÉCNICAS, 2004).

Tabela 1: Resultado material lixiviado e massa bruta

\begin{tabular}{l|l|l|l|l}
\hline Parâmetros & $\begin{array}{l}\text { Limite Máximo } \\
\text { do Lixiviado }\end{array}$ & $\begin{array}{l}\text { Extrato } \\
\text { Lixiviado mg/L }\end{array}$ & $\begin{array}{l}\text { Limite } \\
\text { Máximo } \\
\text { Massa Bruta }\end{array}$ & $\begin{array}{l}\text { Massa Bruta } \\
\mathrm{mg} / \mathrm{Kg}\end{array}$ \\
\hline Arsênio e compostos & $1,0 \mathrm{mg} / \mathrm{L}$ & $\mathrm{ND}$ & -- & -- \\
\hline Bário & $70,0 \mathrm{mg} / \mathrm{L}$ & 2,0 & -- & -- \\
\hline Cádmio & $0,5 \mathrm{mg} / \mathrm{L}$ & 0,0052 & -- & -- \\
\hline Chumbo & $1,0 \mathrm{mg} / \mathrm{L}$ & 0,046 & -- & -- \\
\hline Cianeto (Liberável) & $\mathrm{mg} / \mathrm{L}$ & 0,096 & $250,0 \mathrm{mg} / \mathrm{Kg}$ & 1,92 \\
\hline Cromo Total & $5,0 \mathrm{mg} / \mathrm{L}$ & 0,012 & -- & -- \\
\hline Fluoreto & $150,0 \mathrm{mg} / \mathrm{L}$ & 0,23 & -- & -- \\
\hline Mercúrio & $0,1 \mathrm{mg} / \mathrm{L}$ & $\mathrm{ND}$ & -- & -- \\
\hline Prata & $5,0 \mathrm{mg} / \mathrm{L}$ & 0,0047 & -- & -- \\
\hline Selênio & $1,0 \mathrm{mg} / \mathrm{L}$ & 0,0013 & -- & -- \\
\hline Sulfeto (liberável) & $\mathrm{mg} / \mathrm{L}$ & 0,1 & $500,0 \mathrm{mg} / \mathrm{Kg}$ & 2,0 \\
\hline
\end{tabular}

Fonte: Dos autores 
Tabela 2: Resultado material solubilizado

\begin{tabular}{|l|l|l}
\hline Parâmetros & Limite Máximo do Solubilizado & $\begin{array}{l}\text { Média dos Valores } \\
\text { Encontrados }\end{array}$ \\
\hline Alumínio & $0,2 \mathrm{mg} / \mathrm{L}$ & 4,45 \\
\hline Cádmio & $0,005 \mathrm{mg} / \mathrm{L}$ & 0,0021 \\
\hline Chumbo & $0,01 \mathrm{mg} / \mathrm{L}$ & 0,0095 \\
\hline Cianeto & $0,07 \mathrm{mg} / \mathrm{L}$ & 0,007 \\
\hline Cloreto & $250,0 \mathrm{mg} / \mathrm{L}$ & 16,6 \\
\hline Cobre & $2,0 \mathrm{mg} / \mathrm{L}$ & 0,011 \\
\hline Cromo Total & $0,05 \mathrm{mg} / \mathrm{L}$ & 0,036 \\
\hline Fenol & $0,01 \mathrm{mg} / \mathrm{L}$ & $\mathrm{ND}$ \\
\hline Ferro Total & $0,3 \mathrm{mg} / \mathrm{L}$ & 0,17 \\
\hline Fluoreto & $1,5 \mathrm{mg} / \mathrm{L}$ & 0,065 \\
\hline Manganês & $0,1 \mathrm{mg} / \mathrm{L}$ & 0,07 \\
\hline Mercúrio & $0,001 \mathrm{mg} / \mathrm{L}$ & $\mathrm{ND}$ \\
\hline Nitrato (expresso em N) & $10,0 \mathrm{mg} / \mathrm{L}$ & 1,6 \\
\hline Prata & $0,05 \mathrm{mg} / \mathrm{L}$ & 0,004 \\
\hline Sódio & $200,0 \mathrm{mg} / \mathrm{L}$ & 27,0 \\
\hline Sulfato (expresso em So4) & $250,0 \mathrm{mg} / \mathrm{L}$ & 48,0 \\
\hline Surfactantes & $0,5 \mathrm{mg} / \mathrm{L}$ & $\mathrm{ND}$ \\
\hline Zinco & $5,0 \mathrm{mg} / \mathrm{L}$ & 0,01 \\
\hline
\end{tabular}

Fonte: Dos autores

\subsection{Fluorescência de raios $X$}

A Fluorescência de Raio X - FRX é apresentada na Tabela 3 e confirma a sua origem como resultante do tratamento físico químico do efluente metal mecânico.

Tabela 3: Composição do lodo metal mecânico da ETE (\% em peso)

\begin{tabular}{l|l|l|l|l|l|l|l|l|l}
\hline $\mathrm{Al}^{2} \mathrm{O}^{3}$ & $\mathrm{SO}^{3}$ & $\mathrm{SiO}^{2}$ & $\mathrm{~K}^{2} \mathrm{O}$ & $\mathrm{Fe}^{2} \mathrm{O}^{3}$ & $\mathrm{CaO}$ & $\mathrm{Cr}^{2} \mathrm{O}^{3}$ & $\mathrm{ZnO}$ & $\mathrm{MnO}$ & $\mathrm{CuO}$ \\
98,923 & 0,415 & 0,398 & 0,159 & 0,036 & 0,030 & 0,018 & 0,008 & 0,007 & 0,006 \\
\hline
\end{tabular}


Podemos observar que o lodo é basicamente formado por alumina - $\mathrm{Al}^{2} \mathrm{O}^{3}$. A elevada concentração de alumina está associada ao uso do policloreto de alumínio usado no processo de coagulação físico químico da ETE. Mas também vale ressaltar a presença em baixas concentrações do óxido de silício $\left(\mathrm{SiO}^{2}\right)$ e o hidróxido de potássio $\left(\mathrm{K}^{2} \mathrm{O}\right)$ que se deve ao processo de desengraxe alcalino onde são adicionados o silicato de sódio $\left(\mathrm{Na}^{2} \mathrm{SiO}^{3}\right)$ e o hidróxido de potássio $(\mathrm{KOH})$.

\subsection{Difração de raios $X$}

O difratograma do lodo apresentado na Figura 1, apresenta picos característicos de fase cristalina, podendo-se dizer que há cristais de alumina $\left(\mathrm{Al}^{2} \mathrm{O}^{3}\right)$ e quartzo $\left(\mathrm{SiO}^{2}\right)$. Observa-se ainda a ocorrência da cal $(\mathrm{CaO})$ utilizada para redução do pH no tratamento físico químico, sulfeto de silício $\left(\mathrm{SiS}^{2}\right)$, óxido de zinco $(\mathrm{ZnO})$ proveniente do processo nanocerâmico e óxido de potássio $\left(\mathrm{K}^{2} \mathrm{O}\right)$. Os minerais identificados apresentam-se comparados com padrões do banco de dados do International Center for Diffraction Data - ICDD.

Figura 1: Espectro difração de Raio X do lodo

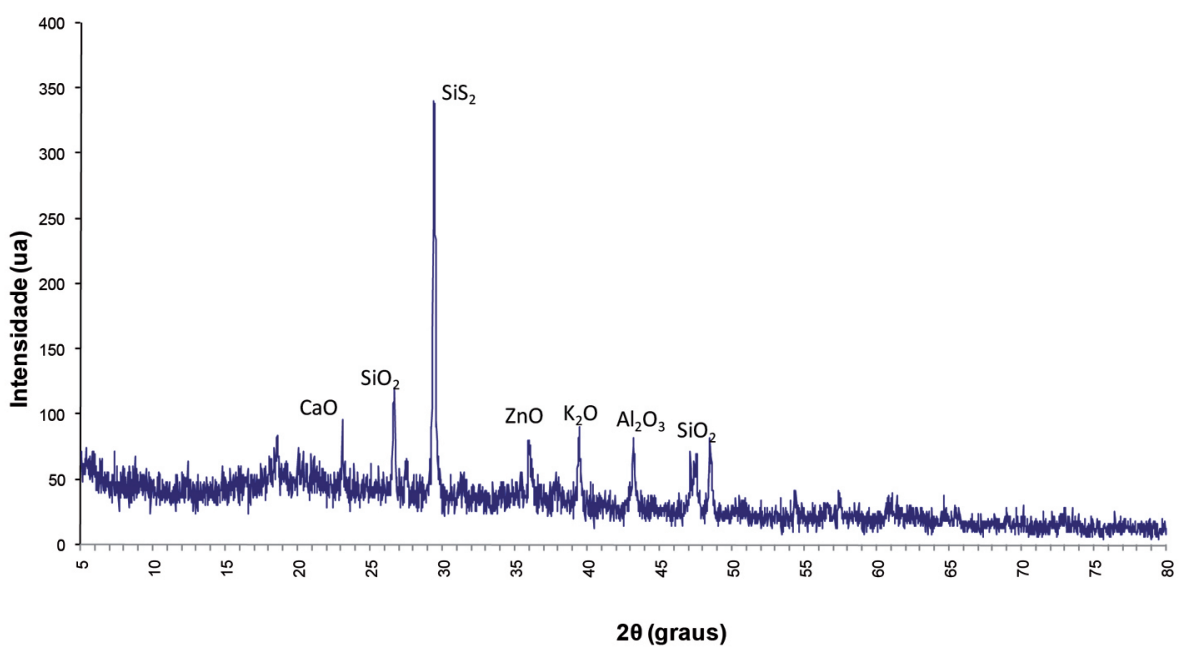

Fonte: Dos autores 


\subsection{Análise térmica}

Os resultados obtidos foram analisados com o software de análise térmica e os dados plotados na Figura $2 \mathrm{com}$ as análises de termogravimetria (TGA) e calorimetria exploratória diferencial (DSC).

Figura 2: TG e DSC do lodo

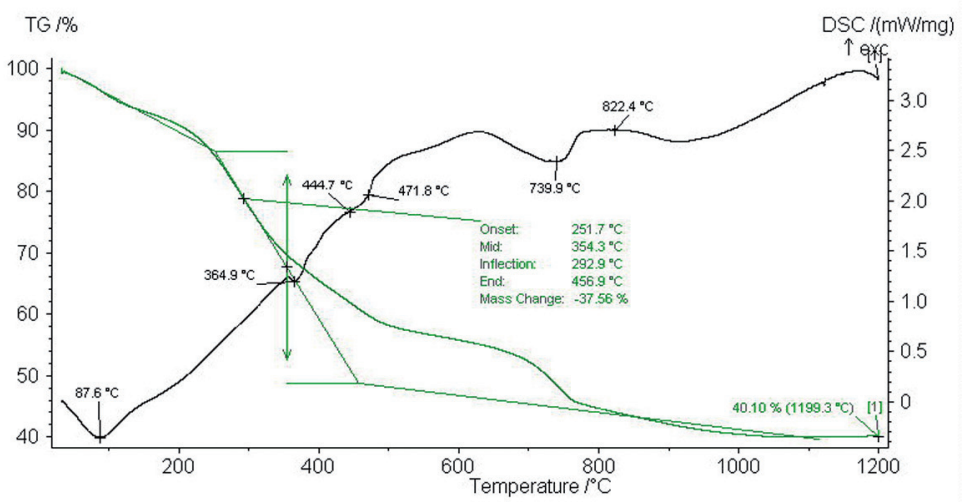

Fonte: Dos autores

A curva TG observada na Figura 2 foi tratada pelo software ${ }^{\circledR}$ Proteus Netzsch e mostrou que houve uma perda total de massa, do resíduo lodo, de $60 \%$ até a temperatura de $1035{ }^{\circ} \mathrm{C}$, a partir desta temperatura a massa permaneceu constante. Até a temperatura de $125{ }^{\circ} \mathrm{C}$ houve um pico endotérmico em $87{ }^{\circ} \mathrm{C}$ resultando na perda de $6 \%$ de massa. Isto está associado à eliminação da água livre contida no lodo. Porém na temperatura de $252{ }^{\circ} \mathrm{C}$ (Tonset) temos início da perda de massa mais expressiva, até a temperatura de $457{ }^{\circ} \mathrm{C}$ (Tpeak), resultando em $37,5 \%$ de perda em massa. Isto está associado à decomposição da matéria orgânica presente na amostra de lodo. Outro pico endotérmico foi identificado na temperatura de $739^{\circ} \mathrm{C}$, entre as temperaturas de 694 e $766^{\circ} \mathrm{C}$ onde a perda de massa foi de $6 \%$ e pode ser atribuída a decomposição de carbonatos presentes na mostra. Acima de $800^{\circ} \mathrm{C}$ não houve perda significativa de massa.

\subsection{Ensaios físicos mecânicos}

Recomenda-se que para produção de tijolos de cerâmica vermelha, os valores da umidade de extrusão fiquem entre 10 e 30 \% (DUARTE, 2008). A Figura 3 apresenta as umidades de extrusão encontradas durante o ensaio. Apenas a composição de $10 \%$ de lodo na argila alcançou resultados dentro dos limites recomendados. 
Figura 3: Umidade de extrusão

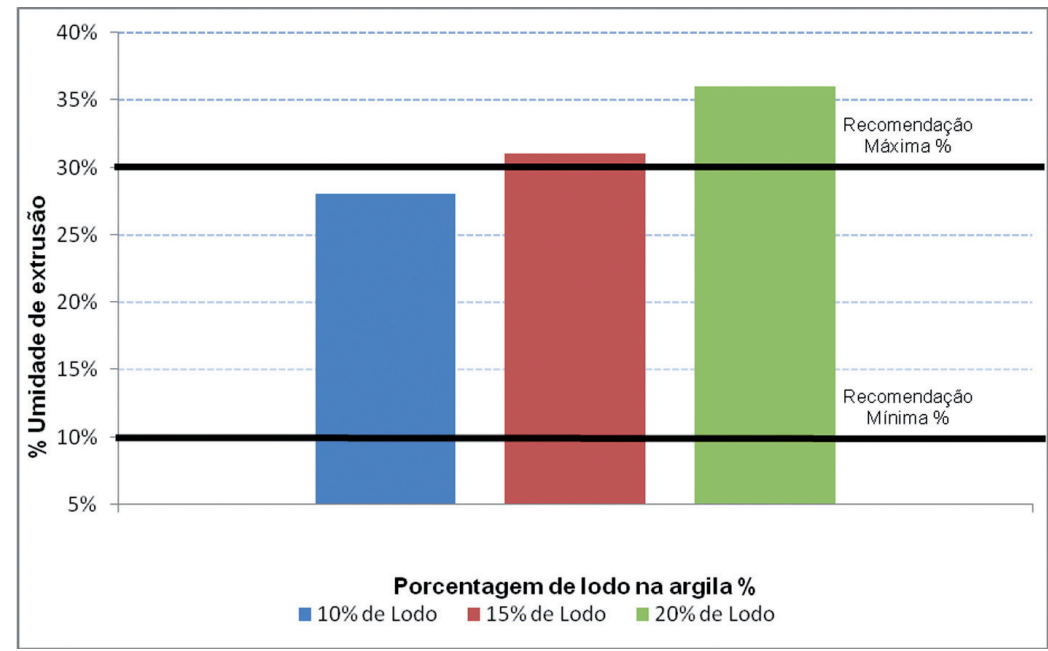

Fonte: Dos autores

A Tabela 4 apresenta a plasticidade das formulações de lodo com argila avaliada através dos limites de Atterberg; limite de liquidez (LL), limite de plasticidade (LP) e índice de plasticidade (IP). Observa-se que todas as formulações apresentaram índices de plasticidade superiores a $15 \%$, limite mínimo para uma argila ser considerada altamente plástica.

Tabela 4: Limite de liquidez e Índice plasticidade das formulações

\begin{tabular}{l|l|l|l|l}
\hline Formulações & LL (\%) & LP (\%) & IP (\%) & Classificação ABNT \\
\hline $10 \%$ & 40,4 & 18,9 & 21,5 & Altamente Plástico \\
\hline $15 \%$ & 40,5 & 21,2 & 19,3 & Altamente Plástico \\
\hline $20 \%$ & 41,4 & 24,3 & 17,1 & Altamente Plástico \\
\hline
\end{tabular}

Fonte: Dos autores

A análise racional, Figura 4, mostrou que as composições ficaram entre 71.40 e 71.67 $\%$. Isto vai de encontro com a alta plasticidade encontrada devido à grande porção de partículas com grãos pequenos. 
Figura 4: Formulações de 10, 15 e 20 \% de lodo na argila retida em peneira

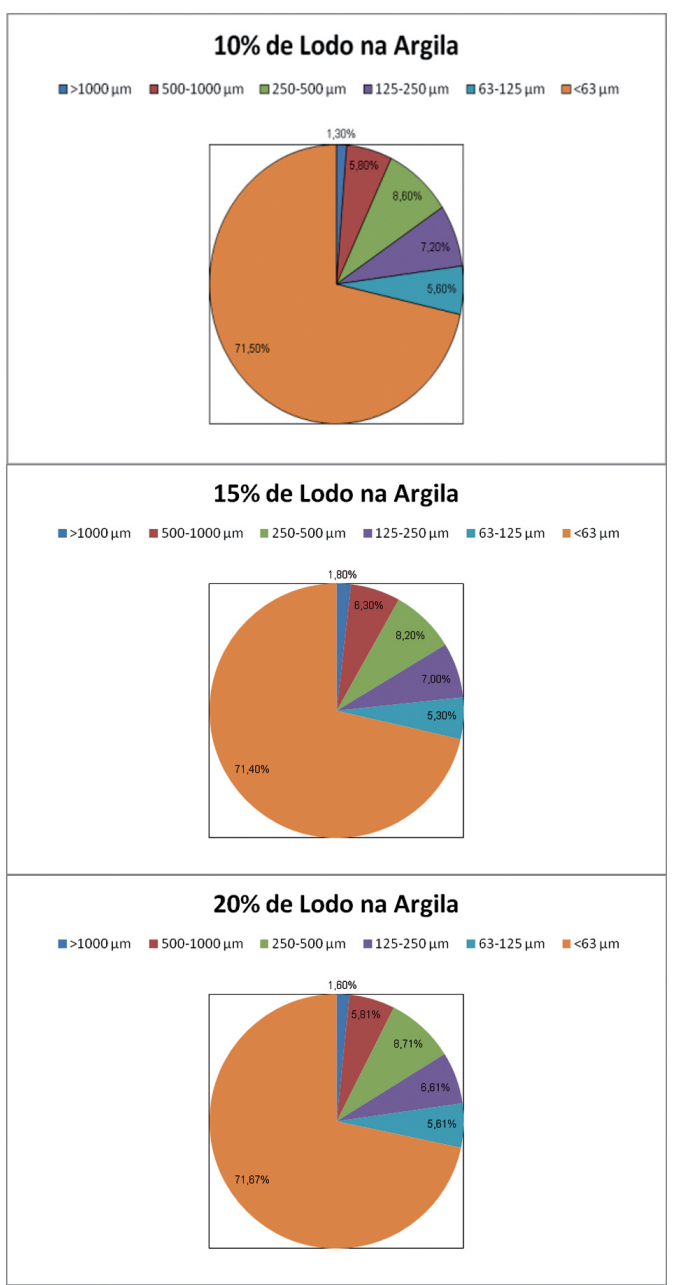

Fonte: Dos autores

Segundo IPT (1985 apud AMORIM, 2007, p.74) para produção de cerâmica vermelha, os valores de retração linear de secagem sejam inferiores a $6 \%$. A Figura 5 apresenta as retrações lineares de secagem dos corpos de prova em relação à porcentagem de lodo na argila. 
Figura 5: Retração linear de secagem

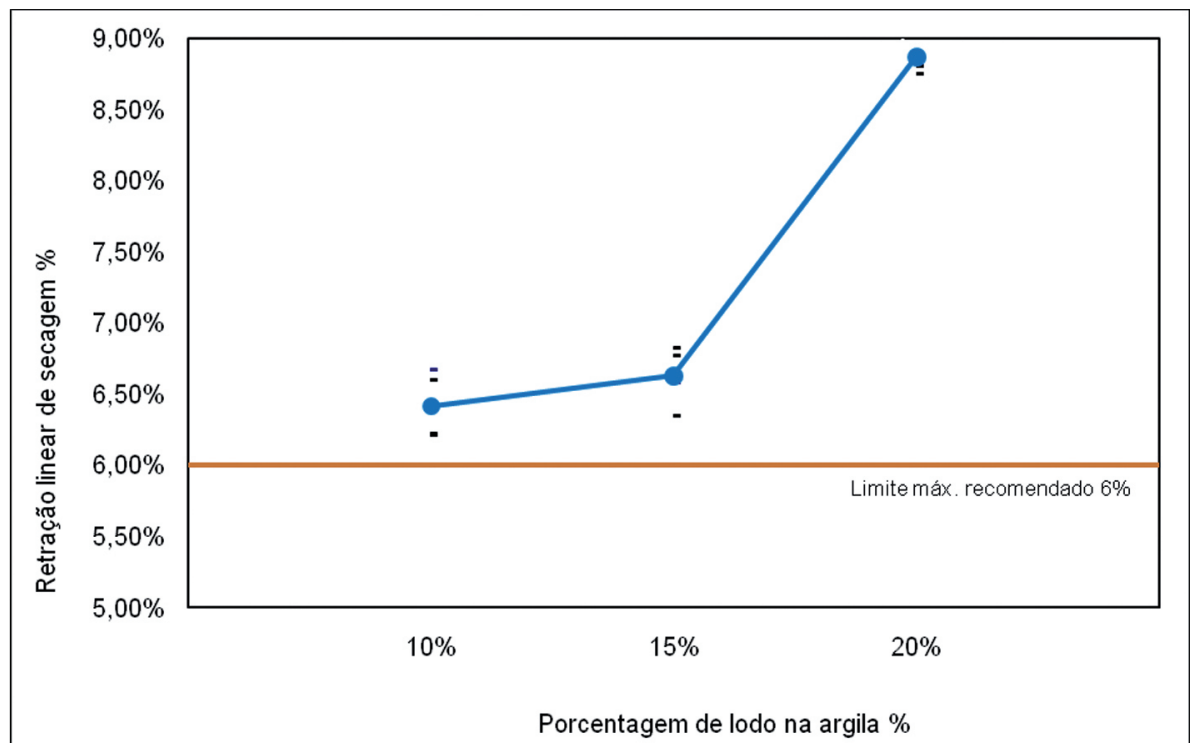

Fonte: Dos autores

Os valores de retração linear de secagem dos corpos de prova para $10.15 \%$ e $20 \%$ não atenderam ao limite máximo recomendado como mostra a Figura 5. Entretanto as composições de $15 \%$ e ainda mais a de $10 \%$ se aproximaram bastante do valor recomendado.

Para produção de tijolos furados, a Associação Brasileira de Normas Técnicas (2005a) indica que os valores de resistência a compressão tenham como mínimo valor $1.5 \mathrm{MPa}$ para furos com uso na horizontal e $3 \mathrm{MPa}$ para uso na vertical, já os tijolos maciços devem possuir 1.5, 2.5 e 4 MPa para as classes A, B e C conforme a Associação Brasileira de Normas Técnicas (1983). A Figura 6 apresenta o valor das resistências à compressão dos corpos de prova em relação à porcentagem de lodo na argila. 


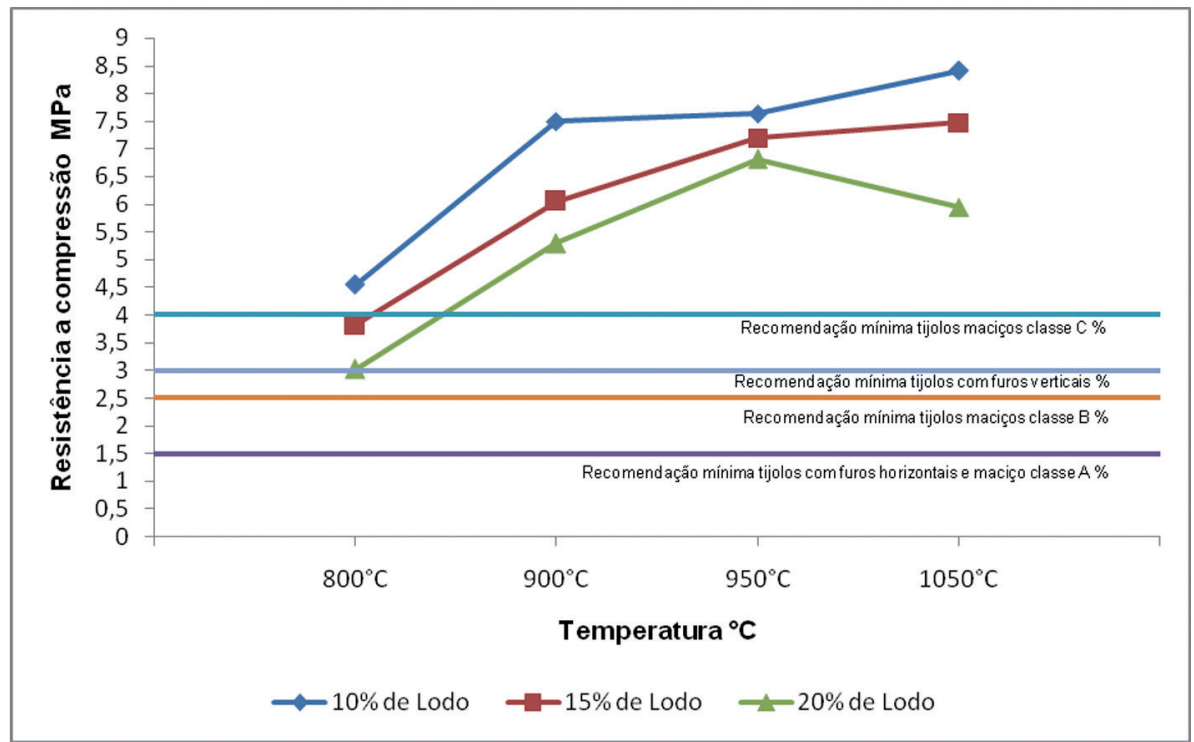

Fonte: Dos autores

Pode-se constatar que a resistência mecânica aumenta com o aumento da temperatura de sinterização. Além disto, quanto menor a quantidade de lodo adicionado na massa maior sua resistência a compressão devido ao menor número de poros abertos pelos compostos carbônicos evaporados e conseqüentemente menores a sua fragilidade.

Observado a aproximação das médias das composições, no gráfico da Figura 6, para temperatura de $950{ }^{\circ} \mathrm{C}$ e foi analisado estatisticamente pelo teste de Tukey com nível de significância de $5 \%$ onde o resultado apontou que não houve evidencia estatística de influência da composição para esta temperatura. Ou seja, a mudança entre as composições de 10, 15 e 20 \% não irá alterar o resultado da resistência a compressão para a queima a $950^{\circ} \mathrm{C}$. Da mesma forma, outro fator observado foi que as composições de 10 e $15 \%$ queimados a temperaturas de 950 e $1050{ }^{\circ} \mathrm{C}$ também não apresentaram diferença estatística.

Recomenda-se que tijolos furados possuam valores de absorção de água entre 8 a 22 \% (ASSOCIAÇÃO BRASILEIRA DE NORMAS TÉCNICAS, 2005a). A Figura 7 apresenta o comportamento da absorção de água média dos corpos de prova e suas porcentagens de lodo na argila em função da temperatura. 
Figura 7: Variação da absorção de água (\%)

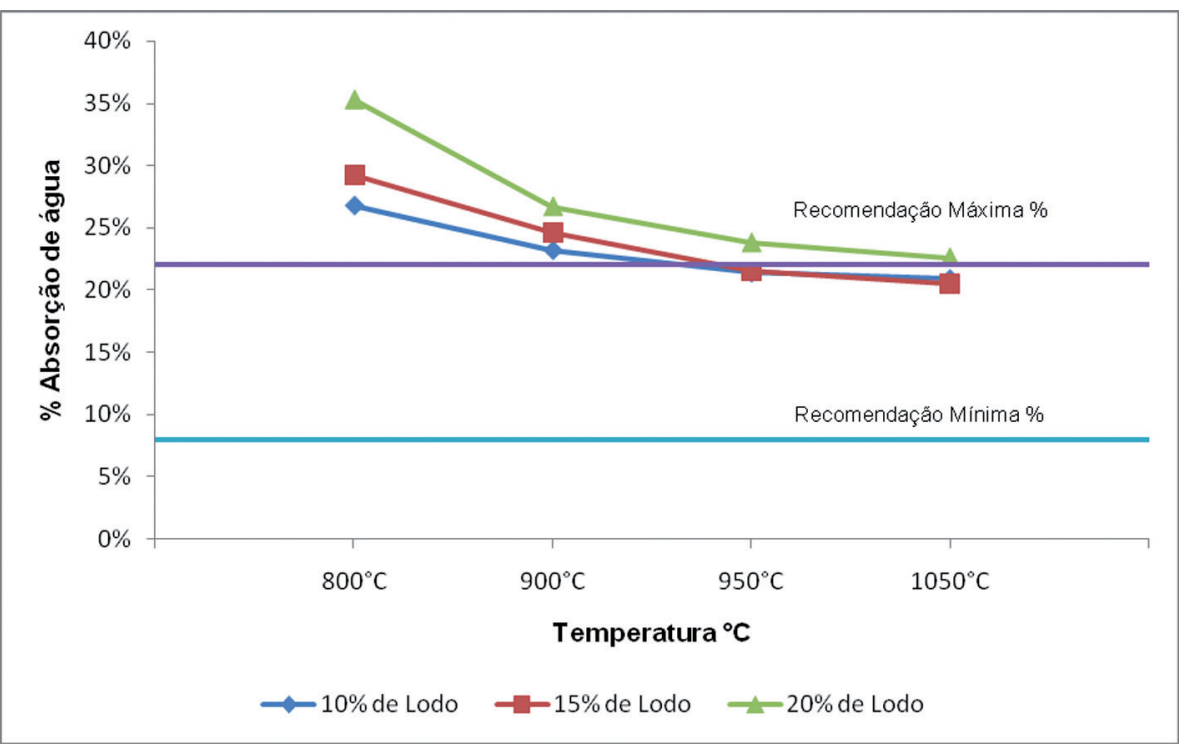

Fonte: Dos autores

Figura 8: Absorção de água (\%)

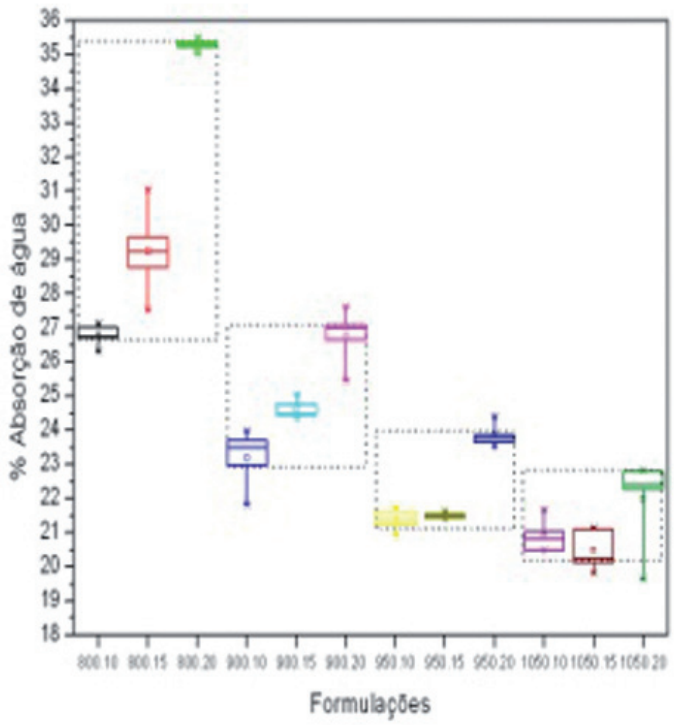

Fonte: Dos autores 
Os resultados mostraram que quanto maior a porcentagem de lodo na argila, maior sua absorção de água para todas as temperaturas de queima, o que está relacionado com o aumento da porosidade dos corpos de prova devido à maior quantidade de resíduo. Notase que os valores de queima a 950 e $1050{ }^{\circ} \mathrm{C}$ apresentaram valores que se enquadram dentro dos limites recomendados. Outro ponto a ser observada, agora na Figura 8 , que utilizando o teste Tukey para um nível de significância de $5 \%$ a temperatura de $1050{ }^{\circ} \mathrm{C}$ não houve evidência estatística de influência da composição de lodo na argila.

De acordo com IPT (1985 apud AMORIM, 2007, p.74) os tijolos furados devem possuir valores de retração linear de queima inferior a $6 \%$. A Figura 9 apresenta as retrações lineares de queima médias com adição de $10 \%, 15 \%$ e $20 \%$ em função da temperatura de queima.

Figura 9: Retração Linear de Queima Média (\%)

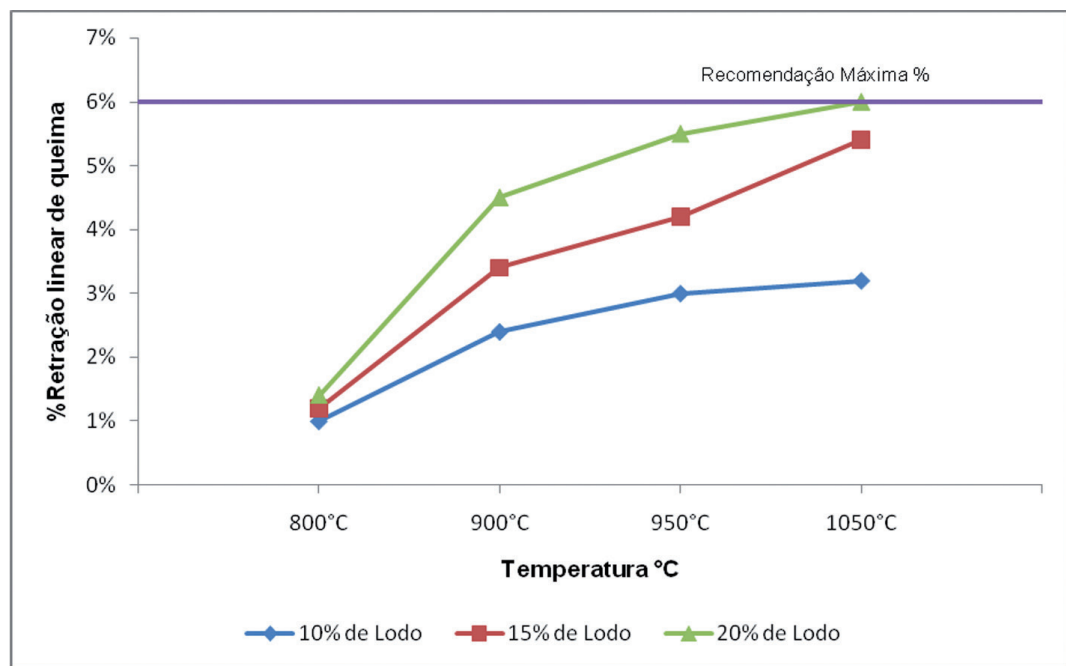

Fonte: Dos autores

Figura 10: Comparação entre variação da retração linear de queima

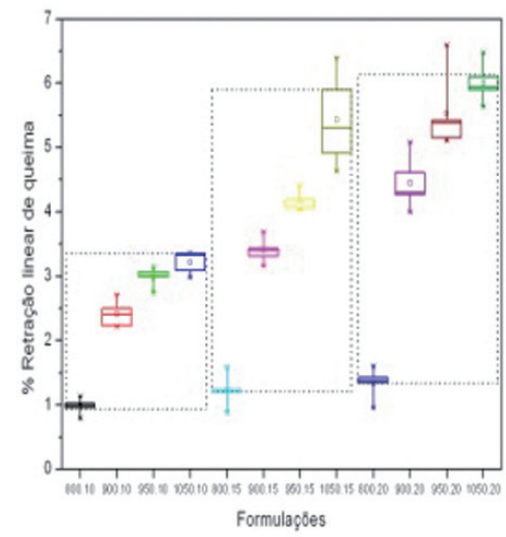

Fonte: Dos autores 
A Figura 9 mostra que todas as temperaturas e composições em média atingiram o valor de retração linear recomendado (6\%).

A Figura 10 mostra a variação entre as formulações e suas temperaturas de queima. Pelo teste de Tukey com nível de significância de 5 \% pode-se constatar que:

a) as retrações lineares de queima se diferenciaram estatisticamente entre as temperaturas e as composições;

b) não houve evidência estatística para influência da temperatura sobre as composições de 10 \% de lodo na argila;

Segundo IPT (1985 apud AMORIM, 2007, p.74) os tijolos furados devem possuir valores de massa específica aparente de $1.7 \mathrm{~g} / \mathrm{cm}^{3}$.

Figura 11: Massa específica aparente $\left(\mathrm{g} / \mathrm{cm}^{3}\right)$

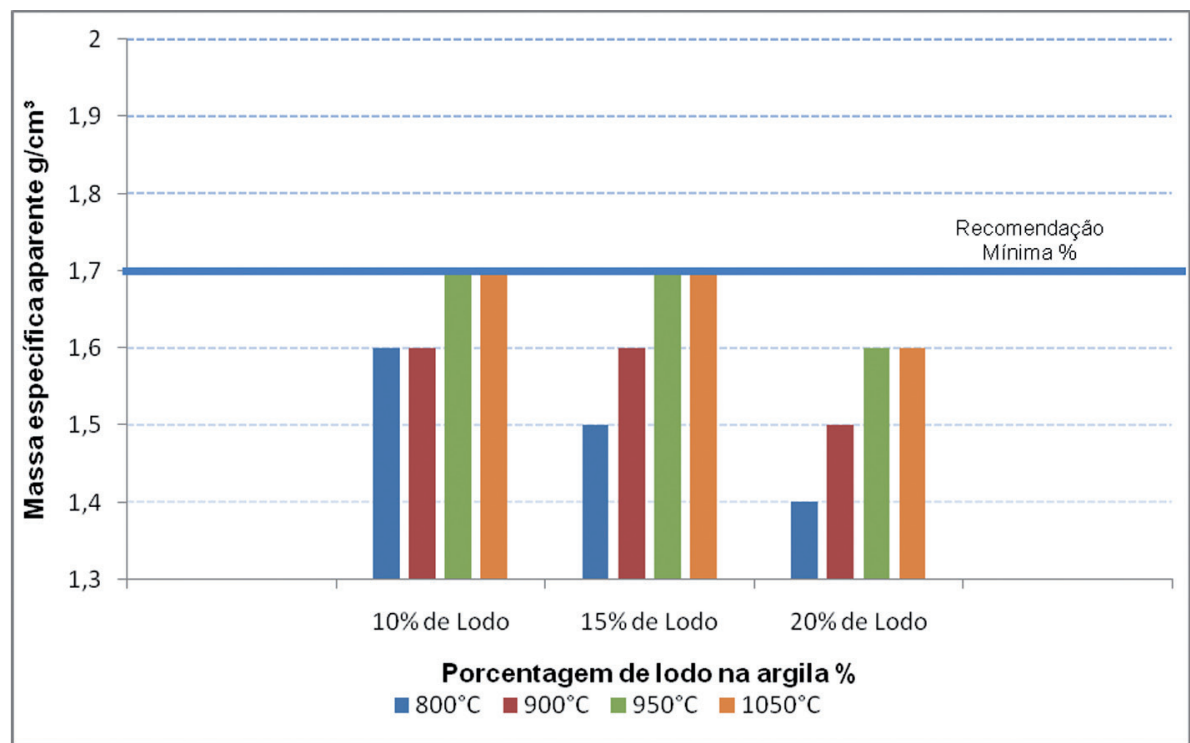

Fonte: Dos autores

Nota-se pela Figura 11 que os corpos de prova queimados a temperatura de 800 e 900 ${ }^{\circ} \mathrm{C}$ não atingiram o valor mínimo recomendado além da composição dos corpos de prova onde a adição do lodo foi de $20 \%$. O aumento da massa específica aparente com o aumento da temperatura relacionada com outros parâmetros como absorção de água e porosidade reforça a hipótese do aumento de poros até a temperatura de fase líquida. A massa cerâmica inicia seu processo de sinterização a partir de $850^{\circ} \mathrm{C}$ e a partir de 950 ${ }^{\circ} \mathrm{C}$ há o início da formação de fase líquida que rapidamente fecha os poros dos corpos cerâmicos. 
Recomenda-se que tijolos furados possuam valores de porosidade aparente entre 17 a 35 \% (IPT, 1985 apud AMORIM, 2007, p. 74). A Figura 12 apresenta o comportamento da porosidade aparente dos corpos de prova e suas porcentagens de lodo na argila em função da temperatura. A porosidade aparente dos corpos de prova de argila com lodo, apresentadas na Figura 32 variou entre 36.6 a 48.5 \%. Os resultados, como já eram de esperar, refletiram a proporcionalidade da absorção de água com tendência a entrar na faixa recomendada com o aumento da temperatura.

Figura 12: Porosidade aparente (\%)

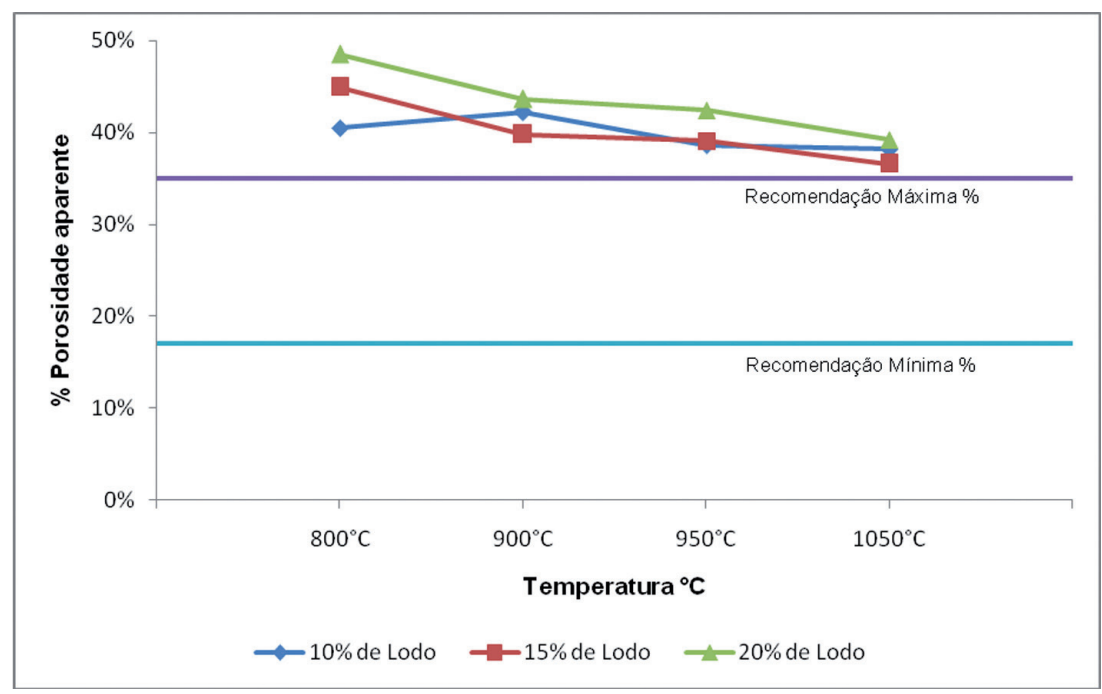

Fonte: Dos autores

Recomenda-se que tijolos furados possuam valores de perda ao fogo de no máximo 10 \% (IPT, 1985 apud AMORIM, 2007, p. 74).

Figura 13: Variação de perda ao fogo média em (\%)

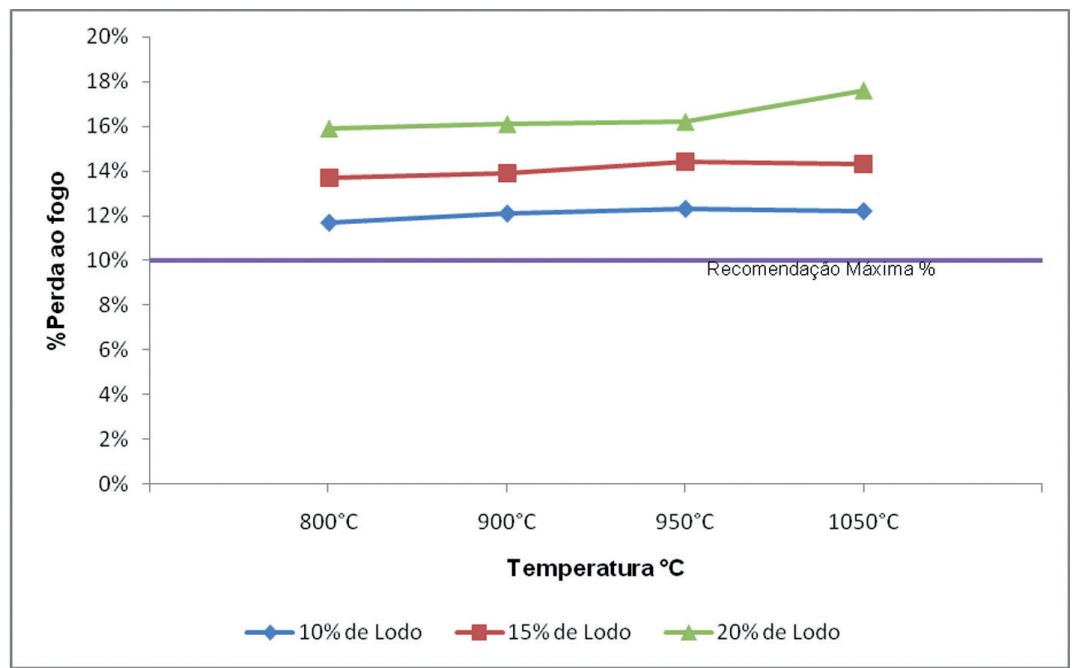

Fonte: Dos autores 
Figura 14: Variação da perda ao fogo função da temperatura

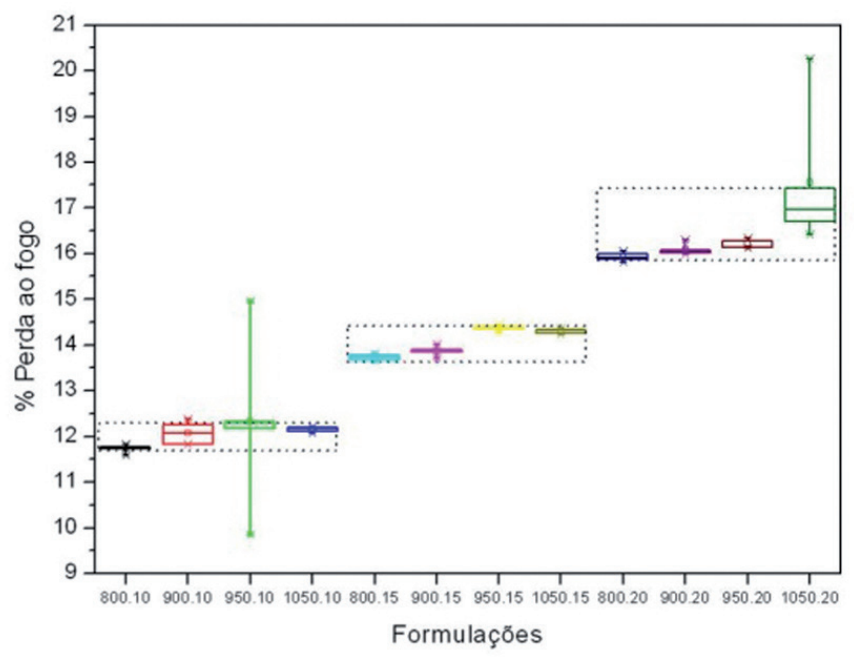

Fonte: Dos autores

A Figura 13 apresenta o comportamento de perda ao fogo médio dos corpos de prova em relação à temperatura de queima. Os resultados não foram favoráveis quanto à adição de lodo na argila, ou seja, ficaram acima do valor recomendado. Pode-se observar que nos resultados existe certa proporcionalidade de perda ao fogo em relação à porcentagem de lodo na argila. Isto pode ser atribuído aos carbonatos existentes no lodo que impactam diretamente na perda de massa em altas temperaturas. Outro fator identificado pela aplicação do teste de Tukey ao nível de significância de $5 \%$, é que não houve evidência estatística de influência da temperatura para a composição de $10 \%$ como mostra a Figura 14.

Segundo Santos (1989, apud GROENNER, 2007, p.63), a cor da cerâmica após a queima para tijolos maciços ou furados deve ser vermelha.

Figura 15: Resultado da cor de queima dos corpos de prova

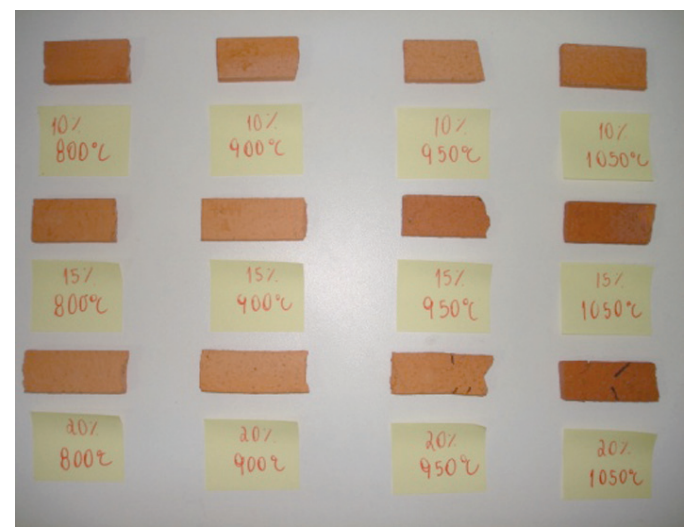

Fonte: Dos autores 
Após a queima os corpos de prova apresentaram coloração marrom claro avermelhado a marrom avermelhado como mostra a Figura 15. Portanto, os corpos de prova com 10,15 e 20 \% de resíduo foram considerados aprovados. Na Tabela 5 apresentam-se os resultados de cor dos corpos de prova após queima.

Tabela 5: Coloração dos corpos de prova após queima

\begin{tabular}{|c|c|c|c|c|}
\hline \multirow{2}{*}{$\begin{array}{l}\text { Percentual } \\
\text { de lodo }\end{array}$} & \multicolumn{4}{|l|}{ Coloração } \\
\hline & Queima $800^{\circ} \mathrm{C}$ & Queima $900^{\circ} \mathrm{C}$ & Queima $950^{\circ} \mathrm{C}$ & Queima $1050^{\circ} \mathrm{C}$ \\
\hline $10 \%$ & $\begin{array}{l}\text { Marrom claro } \\
\text { avermelhado }\end{array}$ & $\begin{array}{l}\text { Marrom claro } \\
\text { avermelhado }\end{array}$ & $\begin{array}{l}\text { Marrom claro } \\
\text { avermelhado }\end{array}$ & $\begin{array}{l}\text { Marrom claro } \\
\text { avermelhado }\end{array}$ \\
\hline $15 \%$ & $\begin{array}{l}\text { Marrom claro } \\
\text { avermelhado }\end{array}$ & $\begin{array}{l}\text { Marrom claro } \\
\text { avermelhado }\end{array}$ & $\begin{array}{l}\text { Marrom } \\
\text { avermelhado }\end{array}$ & $\begin{array}{l}\text { Marrom } \\
\text { avermelhado }\end{array}$ \\
\hline $20 \%$ & $\begin{array}{l}\text { Marrom claro } \\
\text { avermelhado }\end{array}$ & $\begin{array}{l}\text { Marrom claro } \\
\text { avermelhado }\end{array}$ & $\begin{array}{l}\text { Marrom claro } \\
\text { avermelhado }\end{array}$ & $\begin{array}{l}\text { Marrom } \\
\text { avermelhado }\end{array}$ \\
\hline
\end{tabular}

Fonte: Dos autores

O resultado mostrado na tabela 5 apresenta a cor após queima dos corpos de prova. Verifica-se que o incremento de resíduo na argila não apresentou mudanças significativas. Este fato é importante para estética dos produtos comercializados.

\section{CONCLUSÕES}

Todas as condições deste trabalho relativo às condições experimentais, os ensaios e os resultados levam as seguintes conclusões:

Através da avaliação dos resultados de concentração para material solubilizado conforme anexo G da norma ABNT NBR 10004/04 (ASSOCIAÇÃO BRASILEIRA DE NORMAS TÉCNICAS, 2004), o lodo da estação de tratamento de efluentes (ETE) foi caracterizado como pertencente à classe II - Não Inerte.

Uma quantidade considerável de óxido de alumínio foi identificada pela análise química da amostra de lodo, que está associada ao processo de coagulação físico químico da ETE.

Os corpos de prova, em todas as formulações, atenderam aos requisitos recomendados de granulometria, retração linear de queima, massa específica aparente e cor. 
Apesar da composição de $15 \%$ ter resultado num valor bem próximo do limite recomendado, somente os corpos de prova com $10 \%$ de lodo atenderam ao requisito de umidade de extrusão.

Com temperaturas de queima de 950 e $1050{ }^{\circ} \mathrm{C}$, os corpos de prova de 10 e $15 \%$ atenderam os requisitos de absorção de água.

A composição de 20 \% de lodo só atendeu a absorção de água a 1050 C.

A resistência a compressão só não foi atendida pelas composições de 15 e 20 \% de lodo a temperatura de queima de $800^{\circ} \mathrm{C}$.

As composições atenderam a plasticidade recomendada, contudo, a alta plasticidade do material contribui ao não atendimento das características de perda ao fogo, retração de secagem e porosidade.

Além disto, considerando a parcialidade do atendimento as propriedades apresentadas, pode-se dar enfoque ao processo produtivo. Quando por exemplo relacionamos um aumento da temperatura de queima com a porosidade aparente percebemos que existe a tendência de redução deste fator pelo preenchimento dos poros pela maior quantidade de material sinterizado. Além disto, com base na literatura científica (PRACIDELLI; MELCHIADES, 1997 apud ARAUJO, 2008, p. 8) uma adição de argila com plasticidade menor na massa de extrusão contribuiria para alavancar resultados melhores de retração de secagem e perda ao fogo devido à redução da alta plasticidade do material.

Podemos concluir que buscando o aproveitamento do resíduo, e a atingir a otimização do processo de queima, as composições de 10 e $15 \%$ de lodo na argila com temperatura de queima de $950^{\circ} \mathrm{C}$ se aproximam dos requisitos recomendados. Assim com pequenos ajustes de formulação da matéria prima e temperatura de queima, poderíamos atingir as características estabelecidas proporcionando a redução dos custos de matéria prima e contribuindo para amenizar o problema ambiental. 


\title{
STUDY OF THE ADDITION OF SLUDGE GENERATED BY THE METALWORKING INSDUSTRY IN THE MANUFACTURE OF RED CERMIC BRICKS
}

\begin{abstract}
This study aimed to evaluate the incorporation of the ETE (effluent treatment plant) sludge generated at an industrial production plant of refrigerators, to the raw material for the manufacture of red ceramic hollow and solid bricks. The sludge was characterized through the analysis of X-ray fluorescence, X-ray diffraction, and his thermal behaviour studied by thermogravimetry and differential scanning calorimetry. The compositions were prepared in proportions of 10,15 and $20 \%$ of sludge into red ceramic body. Sintered test specimens were produced at temperatures of $800,900,950$ and $1050^{\circ} \mathrm{C}$. For each mixture, the properties of loss to fire, firing shrinkage, drying shrinkage, water absorption, firing colour, density, porosity, particle size, compressive strength, moisture and plasticity were measured. The compositions of 10 and $15 \%$ showed very promising results in relation to specifications. However, to improve the properties of porosity with sintering temperature, and the characteristics of the fire loss and drying shrinkage with the addition of less plastic clays, is the challenge for future work.
\end{abstract}

Keywords: Sludge. Red clay. Bricks. Mechanical properties.

\section{REFERÊNCIAS}

ASSOCIAÇÃO BRASILEIRA DE NORMAS TÉCNICA. NBR 7170: tijolo maciço cerâmico para Alvenaria. Rio de Janeiro, 1983.

NBR 6459: determinação do limite de liquidez. Rio de Janeiro, 1984a.

NBR 7180: determinação do limite de plasticidade. Rio de Janeiro, 1984b.

. NBR 6220: material refratário denso - determinação da massa específica aparente, porosidade aparente, absorção e massa específica aparente da parte sólida. Rio de Janeiro, 1989.

NBR 15270-1: parte 1: blocos cerâmicos para alvenaria de vedação Terminologia e requisitos. Rio de Janeiro, 2005a. 
NBR 15270-3: parte 3: blocos cerâmicos para alvenaria estrutural e de vedação

- Métodos de ensaio. Rio de Janeiro, 2005b.

NBR 10004: resíduos sólidos - classificação. Rio de Janeiro, 2004.

AGUIAR, L. Plano de conservação e reuso de água (PCRA) na Whirlpool unidade de eletrodomésticos. 2007. Monografia (Graduação em Engenharia Ambiental)Universidade da Região de Joinville, Joinville, 2007.

AMORIM, F. R. Co-processamento de dregs em argila para produção de cerâmica vermelha. 2007. Dissertação (Mestrado em Saneamento) - Universidade Federal de Minas Gerais, Belo Horizonte, MG, 2007.

ARAÚJO, F. S. D. Influência do lodo de ETE na massa para fabricação de cerâmica vermelha. 2008. Dissertação (Mestrado em Ciência e Engenharia de Materiais)Universidade Federal do Rio Grande do Norte, Natal, RN, 2008.

BOSSARDI, K. Nanotecnologia aplicada a tratamento superficiais para o aço carbono 1020 como alternativa ao fosfato de zinco. 2007. Dissertação (Mestrado em Engenharia)Universidade Federal do Rio Grande do Sul, Porto Alegre, 2007.

DUARTE, A. C. L. Incorporação do lodo de esgoto na massa cerâmica para fabricação de tijolos maciços: uma alternativa para disposição final do resíduo. 2008. Dissertação (Mestrado em Engenharia Sanitária)-Universidade Federal do Rio Grande do Norte, Natal, RN, 2008.

GROENNER, P. E. M. Reaproveitamento do resíduo de fabricação de consumíveis para soldagem em tijolos de cerâmica vermelha. 2007. Dissertação (Mestrado em Saneamento, Meio Ambiente e Recursos Hídricos) - Universidade Federal de Minas Gerais, Belo Horizonte, MG, 2007.

JIANLONG, W.; JIAZHUO, W. Application of radiation technology to sewage sludge processing: A review. Beijing, China: Laboratory of Environmental Technology, Institute of Nuclear and Energy Technology, Tsinghua University, 2007.

LOPES, D. C. Estudo da viabilidade de adição de resíduo de pó de fumo à massa cerâmica. 2005. Dissertação (Mestrado em Engenharia Civil)-Universidade Federal de Santa Maria, Santa Maria, RS, 2005.

NAIR, A.; JUWARKAR, A. A.; DEVOTTA, S. Study of speciation of metals in an industrial sludge and evaluation of metal chelators for their removal. Índia: National Environmental Engineering Research Institute (NEERI), 2007.

PARANHOS, R. J. S. Aproveitamento de resíduo de cinza da cana de açúcar em massas cerâmicas. 2010. Dissertação (Mestrado em Engenharia Mecânica)- Universidade do Rio Grande do Norte, Natal, RN, 2010. 
RIBEIRO, R. A. Desenvolvimento de novos materiais cerâmicos a partir de resíduos industriais metal mecânicos. 2008. Dissertação (Mestrado em Engenharia e Ciência dos Materiais)-Universidade Federal do Paraná, Curitiba, PR, 2008.

STARK, K. Phosphorus release and recovery from treated sewage sludge. Estocolmo, Suécia, PhD, TRITA-LWR PhD Thesis 1024, 2005.

TARTARI, R. Incorporação de lodo gerado na estação de tratamento de água Tamanduá, como aditivo em massas para cerâmica vermelha. 2008. Dissertação (Mestrado em Engenharia Química)-Universidade do Oeste do Paraná, Toledo, PR, 2008.

\section{SOBRE OS AUTORES}

\begin{tabular}{|ll}
\hline & $\begin{array}{l}\text { Mestre em Engenharia de Processos pela UNIVILLE, Especialista em Engenharia } \\
\text { de Automação pela SOCIESC, Tecnólogo em Processos Industriais com Habilitação } \\
\text { em eletromecânica pela UNIVILLE/SENAl. Professor Especialista de Ensino do } \\
\text { Núcleo de Automação e Mecatrônica do SENAI, Joinville, atualmente é docente } \\
\text { nas disciplinas para os Cursos de Pós Graduação e Superiores de Tecnologia } \\
\text { em Mecatrônica Industrial, Redes de Computadores e Fabricação Mecânica e } \\
\text { também para os cursos técnicos em Automação Industrial e Mecatrônica. } \\
\text { Há mais de } 10 \text { anos, exerce a função Especialista de Manutenção na Empresa } \\
\text { Mexichem Brasil, desenvolvendo e gerenciando diversos projetos de melhorias } \\
\text { de processos de Extrusão, Injeção e Sopro. Atua fortemente em projetos de } \\
\text { adequação de equipamentos às normas NR 10 e NR12. } \\
\text { Consultor de empresas no segmento de metalmecânica, automação e de } \\
\text { processos da região norte de Santa Catarina, com ênfase em instrumentação } \\
\text { e controle de processos automatizados, adequação às normas NR 10 e NR12. }\end{array}$ \\
Geovane Vieira
\end{tabular}

Mestre em Engenharia de Processos pela Universidade da Região de Joinville -
Univille. Especialista em Engenharia de Produção pela Universidade do Estado
de Santa Catarina - UDESC, Engenheiro Químico pela Universidade Regional
de Blumenau - FURB. Engenheiro de Processos Sênior na Whirlpool SA há 11
anos. Atua no desenvolvimento de processos de montagem para refrigeradores
e freezers da marca Consul e Brastemp, implantação de novos produtos e
manutenção dos processos.

